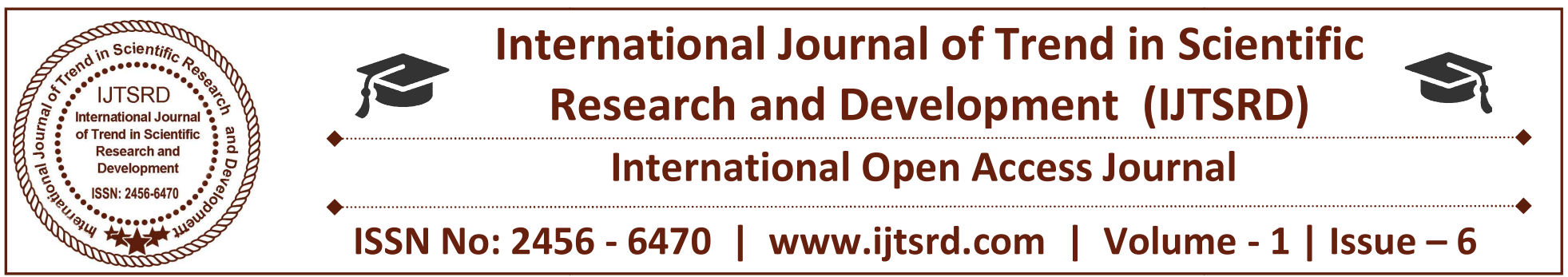

\title{
A Study of Pre Enginered Building
}

\author{
C. Mohanraj \\ PG Student, Department of Civil Engineering, \\ Bannariamman Institute of Technology, \\ Sathyamangalam, Tamilnadu
}

\author{
V. Preetha \\ Assistant Professor, Department of Civil Engineering, \\ Bannariamman Institute of Technology, \\ Sathyamangalam,Tamilnadu
}

\begin{abstract}
The pre-engineered building system is, without doubt, one of the fastest growing building systems in the world. The advantages that it offers appeal to all parties involved in the project. After all, who can resist a building system that offers speed, quality and value. Applications of pre-engineered buildings are numerous. Described in few words, pre-engineered buildings are ideal for any non-residential low-rise building. After introducing the concept of pre engineered building (PEB), the design helps to optimizing design. The adoptability of PEB in the place of Conventional Steel Building (CSB) design concept resulted in many advantages, including economy and easier fabrication. Possibilities of long span column free structures more essential for industrial structures. PEB concept is versatile not only due to its quality pre-designing and prefabrication, but also due to its light weight and economical construction.
\end{abstract}

Keywords: Pre-Engineered Building, Conventional Steel Building

\section{INTRODUCTION}

Technological improvement over the year has contributed immensely to the enhancement of quality of life through various new products and services. One such revolution was the PEB buildings. Through its origin can be traced back to 1960's its potential has been felt only during the recent years. This was mainly due to the development in technology, which helped in computerizing the design and design.
Though initially only off the shelf products were available in these configurations aided by the technological development tailor made solutions are also made using this technology in very short durations. A recent survey by the Metal Building Associations (MBMA) shows that about $60 \%$ of the non residential low rises building in USA are PEB buildings.

Although PEB systems are extensively used in industrial and many other non residential constructions worldwide, it is relatively a new concept in India. These concepts were introduced to the Indian markets lately in the late 1990's with the opening up of the economy and a number of multi nationals setting up their projects. The market potential of PEB's is 1.2 million tonnes per annum. The current PEB manufacturing capacity is 0.35 million tonnes per annum. The industry is growing at the compound rate of 25 to $30 \%$.

With respect to design of the structure and aesthetic appearance India is way behind. Indian manufacturers are trying to catch up; comparatively PEB's is a new concept in India. Beside, in fabrication and other areas of PEB India is very good. As compared to other countries Indian codes for building design are stringent but safer. IS standards are upgraded continuously. In India, American codes are also followed. 


\section{REVIEW OF LITERATURE}

2.1. Pradip S. Lande, Vivek V. Kucheriya(2015)observed that, comparative study of conventional and PEB, as an Economic aspects of cold formed sections as purlins in comparison with traditionally used hot rolled section for industrial structure are measured in terms of weight. The paper says that PEB structure weight is $35 \%$ less than the CSB structures. As compared to that of AISC/MBMA the structure weight be higher in IS 800-2007 due to limiting ratios of the section selection. Most probably the weight of PEB depends mainly on bay spacing, where upto and certain limit after that weight be increased. As that for to decreased the weight of structure by provide secondary member as light gauge section of Z-purlin.

2.2. Aijaz Ahmad Zende, Prof. A. V. Kulkarni ,AslamHutagi(2013) observed that comparative study of design of PEB and conventional frames by staad pro. The use of PEB not only reduces the weight of the structure because high tensile steel grades are used but also ensures quality control of the structure. In the present study, comparison has been made for different bay spacing of $8 \mathrm{~m}, 8.88 \mathrm{~m}, 10 \mathrm{~m}, 11.425 \mathrm{~m}, 13.33 \mathrm{~m}$ considering the length of building as $80 \mathrm{~m}$. In that $8.88 \mathrm{~m}$ spacing gives less weight followed by bay spacing of $11.425 \mathrm{~m}$ whereas $8 \mathrm{~m}$ spacing gives more weight. The paper concludes that the weight of PEB depends on bay spacing so that increase in Bay Spacing up to certain spacing, the weight reduces and further increase makes the weight heavier.

\subsection{J.Jayavelmurugan, J.R.Thirumal,} Padmanabhanharidas(2015) observed that PEB use a combination of built-up sections, hot rolled sections and cold formed Elements. PEB can be fitted with different structural accessories including mezzanine floors, canopies, fascia's, interior partitions etc. and the building is made water proof by use of special mastic beads, filler strips and trims. PEB are generally low rise buildings however the maximum eave height can go up to 25 to 30 metres. Low rise buildings are ideal for offices, houses, showrooms, shop fronts etc. The application of pre engineered buildings concept to low raise buildings is very economical and speedy. PEB would be the only solution for large industrial enclosures having thermal and acoustical features. The major advantage of metal building is the high speed of design and construction for buildings of various categories.
2.4. D V SWATHI(2014) observed thatPreengineered steel structures building offers low cost, strength, durability, design flexibility, adaptability and recyclability. The paper explains the comparison of 2D Plane Frame is made for both pre-engineered building and conventional type. The plane frame is having width $38.1 \mathrm{~m}$ and bay spacing $6.25 \mathrm{~m}$ and eave height $8.2 \mathrm{~m}$. Based on the analytical and design results PEB depends on the Bay Spacing, with the increase in Bay Spacing up to certain spacing, the weight reduces and further increase makes the weight heavier.

2.5. Pradeep V, Papa Rao G (2014) observed that an industrial building of length $44 \mathrm{~m}$ and width $20 \mathrm{~m}$ with roofing system as conventional steel truss and preengineered steel truss is analysed and designed by used STAAD Pro V8i.V.The different load case could be analysed, it is observed that the Axial force at supports in PEB is less when compared to that in CSB with concrete columns and steel columns. Shear force at supports in PEB is less when compared to that in CSB with concrete columns and steel columns. The Bending Moments at supports in PEB is negligible when compared to that in CSB with concrete columns and steel columns. This paper effectively conveys that PEB structures can be easily designed by simple design procedures in accordance with country standards. Low weight flexible frames of PEB offer higher resistance to earthquake loads. PEB roof structure is almost $26 \%$ lighter than Conventional Steel Building. In secondary members, light weight "Z" purlins are used for PEB structure, whereas heavier hot-rolled sections are used for CSB.

\subsection{Kavya.Rao.M.N, K.N.Vishwanath(2014)} observed that PEB's reduce the steel used by $36 \%$ than that required for the CSB. The bending and shear force of PEB are lesser than the CSB which in turn reduces the material required for the structure. The lighter tapered sections offer better resistance to earthquake forces than the heavy frames of CSB in the earthquake zones. Savings in cost for PEB can be done in many ways such as savings in material, providing lighter foundation etc. Also the PEB's are aesthetically pleasing at a lesser cost. Upto $30 \%$ cost reduction can be achieved using PEB.

\section{PARAMETERS OF PRE ENGINEERED BUILDINGS}




\section{Building Width:}

No matter what primary framing system is used, the building width is defined as the distance from outside of eave strut of one sidewall to outside of eave strut of the opposite sidewall. Building width does not include the width of Lean-To buildings or roof extensions.

\section{Building Length:}

The longitudinal length of the building measured from out to out of end wall steel lines.

\section{Building Height:}

Building height is the eave height which usually is the distance from the bottom of the main frame column base plate to the top outer point of the eave strut. When columns are recessed or elevated from finished floor, eave height is the distance from finished floor level to top of eave strut.

\section{Roof Slope (x/10):}

This is the angle of the roof with respect to the horizontal. The most common roof slopes are $0.5 / 10$ and $1 / 10$. Any practical roof slope is possible.

\section{End bay length:}

The distance from outside of the outer flange of end wall columns to center line of the first interior frame column

\section{Interior bay length:}

The distance between the center lines of two adjacent interior main frame columns. The most common bay lengths are $6 \mathrm{~m}, 7.5 \mathrm{~m}$ and $9 \mathrm{~m}$.

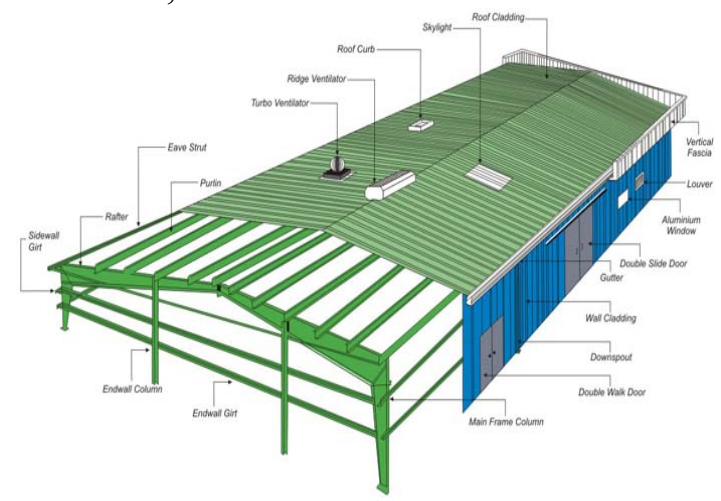

\section{Secondary Framing}

Purlins, girts and eave struts are secondary structural members used to support the wall and roof panels. Purlins are used on the roof; girts are used on the walls and eave struts are used at the intersection of the sidewall and the roof. Secondary members have two other functions:
1) Act as struts that help in resisting part of the longitudinal loads that are applied on the building such as wind and earthquake loads.

2) Provide lateral bracing to the compression flanges of the main frame members thereby increasing frame capacity.

3) Purlins, girts and eave struts are available in high grade steel conforming to ASTM A 607 Grade 50 or equivalent, available in $1.5 \mathrm{~mm}, 1.75 \mathrm{~mm} .2 .0 \mathrm{~mm}$, $2.25 \mathrm{~mm}, 2.5 \mathrm{~mm}$ and $3.0 \mathrm{~mm}$ thickness. pre-They come with a pre-galvanized finish, or factory painted with a minimum of 35 microns (DFT) of corrosion protection primer.
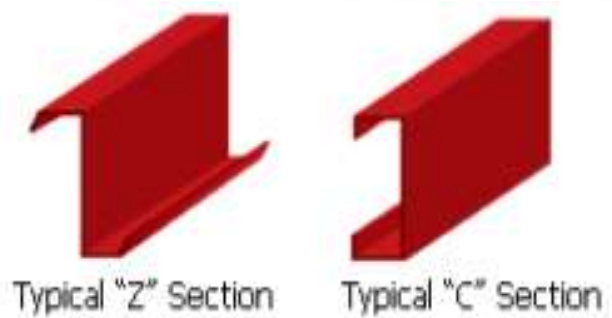

\section{APPLICATIONS OF PRE ENGINEERED BUILDING}
a) Factory buildings
b) Warehouses
c) Workshops
d) Production Units
e) Showrooms
f) Garages
g) Car Parking Space
h) Supermarkets
i) Community Halls
j) Auditoriums
k) Service Centre
1) Textiles Dying \& Weaving Units
m) Testing Laboratories
n) Spinning Mills
o) Institutions
p) Function Halls
q) Aircraft Hangars
r) Metro Stations

\section{ADVANTAGES OF PEB \\ Design:}

Since PEB's are mainly formed of standard sections and connections, the design time is significantly reduced. Specialized computer analysis and design programs optimize material require. Drafting also computerized using standard details that minimizes project custom details. The low-weight flexible frames offer higher resistance to seismic forces. 


\section{Lower Cost:}

Due to the systems approach, there is a significant saving in design, manufacturing and site erection cost. The structural elements are shaped to follow the stress diagram of the member, thus reducing weight, cost and load to foundations. The secondary members and cladding nest together reducing transportation cost. The overall price per square meter may be reduced as much as $30 \%$ lower than conventional steel.

\section{Foundations:}

Pre-engineered Buildings are about 30\% lighter than the conventional steel structures. Hence, the foundations are of simple design, easy to construct and lighter weights.

\section{Erection:}

Since all the connections of the different components are standard, the erection time is faster.

\section{Flexibility of Expansion:}

Buildings can be easily expanded in length by adding additional bays. Also, expansion in width and height is possible by pre-designing for future expansion.

\section{Large Clear Spans:}

Buildings can be supplied to around 90M clear spans.

\section{Quality Control:}

As buildings are manufactured completely in the factory under controlled conditions, the quality is assured.

\section{Low Maintenance:}

Buildings are supplied with high quality paint systems for cladding and steel to suit ambient conditions at site, which results in long durability and low maintenance costs.

\section{Energy Efficient Roof and Wall Systems:}

Buildings can be supplied with polyurethane insulated panels or fibreglass blanket insulation to achieve required 'U' values.

\section{Architectural Versatility:}

Buildings can be supplied with various types of fascia's, canopies, and curved eaves and designed to receive pre-cast concrete wall panels, curtain walls, block walls and other wall systems.

\section{Single Source Responsibility:}

As the complete building package is supplied by a single vendor compatibility of all the building components and accessories is assured. This is one of the major benefits of the pre-engineered building systems.

\section{CONCLUSION}

Pre-engineered steel structures building offers low cost, strength, durability, design flexibility, adaptability and recyclability. Steel is the basic material that is used in the materials that are used for Pre-engineered steel building. It negates from regional sources. Infinitely recyclable, steel is the material that reflects the imperative of sustainable development.

\section{REFERENCE}

1) Meera C.M, "Pre-Engineered Building Design of an Industrial Warehouse", International journal of Engineering Sciences and Emerging Technologies, Volume 5, Issue 2, June - 2013, pp: 75- 82.

2) Aijaz Ahmad Zende, Prof. A. V. Kulkarni, AslamHutagia, "Comparative Study of Analysis and Design of Pre-Engineered- Buildings and Conventional Frames", IOSR journal of mechanical and civil engineering, Volume 5, Issue 1, Jan.- Feb. 2013, pp: 32- 43.

3) Swathi D.V, "Design and analysis of preengineered steel frame"International Journal of Research Sciences and Advanced Engineering,[Volume 2 , Issue 8,OCT -DEC 2014 pp: $250-255$.

4) Kavya.Rao.M.N, K.N.Vishwanath, "Design Optimisation of an Industrial Structure from Steel Frame to Pre-Engineered Building", International Journal of Research in Advent Technology, Vol.2, No.9, September 2014 E-ISSN: 2321-9637.

5) Pradeep V, Papa Rao G, "Comparative Study of Pre Engineered and Conventional Industrial Building", International Journal of Engineering Trends and Technology -Volume 9 Number 1 Mar 2014.

6) Kavya.Rao.M.N, K.N.Vishwanath, "Design Optimisation of an Industrial Structure from Steel Frame to Pre-Engineered Building" International Journal of Research in Advent Technology, Vol.2, No.9, September 2014 E-ISSN: 2321-9637. 